\title{
Economic assessment of climate adaptation options for urban drainage design in Odense, Denmark
}

\section{Zhou, Qianqian; Halsnæs, Kirsten; Arnbjerg-Nielsen, Karsten}

\section{Published in:}

Water Science and Technology

Link to article, DOI:

10.2166/wst.2012.386

Publication date:

2012

Document Version

Publisher's PDF, also known as Version of record

Link back to DTU Orbit

Citation (APA):

Zhou, Q., Halsnæs, K., \& Arnbjerg-Nielsen, K. (2012). Economic assessment of climate adaptation options for urban drainage design in Odense, Denmark. Water Science and Technology, 66(8), 1812-1820.

https://doi.org/10.2166/wst.2012.386

\section{General rights}

Copyright and moral rights for the publications made accessible in the public portal are retained by the authors and/or other copyright owners and it is a condition of accessing publications that users recognise and abide by the legal requirements associated with these rights.

- Users may download and print one copy of any publication from the public portal for the purpose of private study or research.

- You may not further distribute the material or use it for any profit-making activity or commercial gain

- You may freely distribute the URL identifying the publication in the public portal 


\title{
Economic assessment of climate adaptation options for urban drainage design in Odense, Denmark
}

\author{
Q. Zhou, K. Halsnæs and K. Arnbjerg-Nielsen
}

\begin{abstract}
$\overline{\text { ABSTRACT }}$
Climate change is likely to influence the water cycle by changing the precipitation patterns, in some cases leading to increased occurrences of precipitation extremes. Urban landscapes are vulnerable to such changes due to the concentrated population and socio-economic values in cities. Feasible adaptation requires better flood risk quantification and assessment of appropriate adaptation actions in term of costs and benefits. This paper presents an economic assessment of three prevailing climate adaptation options for urban drainage design in a Danish case study, Odense. A risk-based evaluation framework is used to give detailed insights of the physical and economic feasibilities of each option. Estimation of marginal benefits of adaptation options are carried out through a step-by-step cost-benefit analysis. The results are aimed at providing important

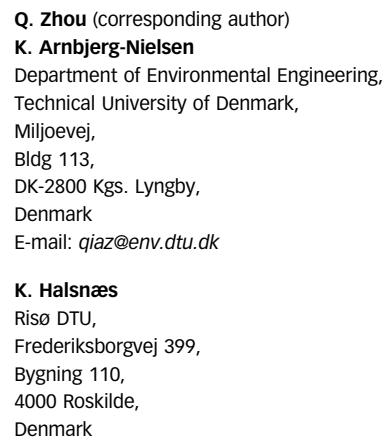

Department of Environmental Engineering

Miljoevej,

Denmark

Frederiksborgvej 399,

4000 Roskilde

Denmark

K. Arnbjerg-Nielsen
\end{abstract} information for decision making on how best to adapt to urban pluvial flooding due to climate impacts in cities.

Key words | climate change adaptation, flood risk assessment, flood risk management, socio-economic framework, urban drainage design

\section{INTRODUCTION}

Climate change is anticipated to significantly affect the precipitation patterns (Ashley et al. 2005; Arnbjerg-Nielsen 2006; Madsen et al. 2009). In Northern Europe, many cities have already experienced an increase in flood frequency and magnitude (Arnbjerg-Nielsen 2006; Ashley et al. 2007; Burrell et al. 2007; Lenderink \& Van Meijgaard 2008; Jones et al. 2010). Even though mitigation has been adopted globally as a strategy for tackling climate impacts, through the reduction of greenhouse gases, adaptation is significant to complement mitigation to cope with the unavoidable impacts in the short and long term (European Commission 2009; Hall et al. 2006). This indicates a high need for identification of feasible socio-economic assessments of climate adaptation, in terms of costs and benefits, to supplement and further develop existing design practices for urban drainage.

It has been widely acknowledged in the context of climate change that flood risk depends on the exposure of vulnerabilities to hazards (Barroca et al. 2006; Hauger et al. 2006; Haynes et al. 2008; FLOODsite 2009). As a result, the management of flood risk can be achieved through appropriate activities that mitigate hazards and/or vulnerabilities. A number of adaptation actions have been initiated in attempts to study fluvial and tidal floods in large scales (Hall et al. 2006; Jonkman et al. 2008; Morita 2008; Dawson et al. 2009). However, few climate adaptation studies have been conducted for pluvial floods in an urban setting due to the complex 'dose-response' dynamics in sewer networks and various local contexts in cities. A large variety of adaptation measures exist to cope with climate change impacts; however, their effectiveness depends to a large extent on the context of a concrete situation (FLOODsite 2009). Climate change adaptation is often costly to implement. It requires a thorough analysis of adaptation measures in terms of their applicability and efficiency to allow appropriate decisions on adaptation. Zhou et al. (2012) have suggested a framework for pluvial flood risk management to quantify climate impacts and adaptation benefits for urban drainage design. The framework integrates the work in the field of climate change impacts assessment, flood inundation modelling, socio-economic tools, and risk assessment and management.

This paper presents an application of the integrated framework in a Danish case study, Odense, and focuses on the 
economic assessment of three prevailing types of climate adaptation options for urban drainage design in the area. A detailed economic analysis was carried out to give insights into the pros and cons of each option.

\section{METHODS}

Figure 1 shows the procedure of the generic framework applied for the pluvial flood risk assessment of climate change impacts and adaptation benefits (Zhou et al. 20I2) in this study. Flood risk is assessed based on an analysis of hazards and vulnerabilities (Plate 2002; Haynes et al. 2008). The key principle of the risk assessment framework is to assess the hazard of a given external climatic loading and the vulnerability based on a given physical and socioeconomic condition. More specifically, the flood hazard describes the probability, magnitude (e.g. depth, velocity) and extent of flooding in the form of flood hazard maps simulated on the basis of inundation modelling. The vulnerability describes the potential adverse effects that can occur given exposure to the hazard. In most cases, the vulnerability is described by the economic, social and ecological costs by means of land-use maps and other information. The simulated hazard maps with the socio-economic data and flood criteria are combined in a Geographical Information System (GIS)-based model to identify affected vulnerabilities as a result of exposure, by extracting a spatial coordinated layer/map containing flooded categories of interest. Flood damage costs of a given hazard are calculated by converting the affected vulnerability into monetary terms, and hence the risk of flooding can be estimated by integrating the damage costs and the corresponding probability of occurrence. Finally, by integrating the risk of flooding over return periods, the expected annual damage (EAD) is

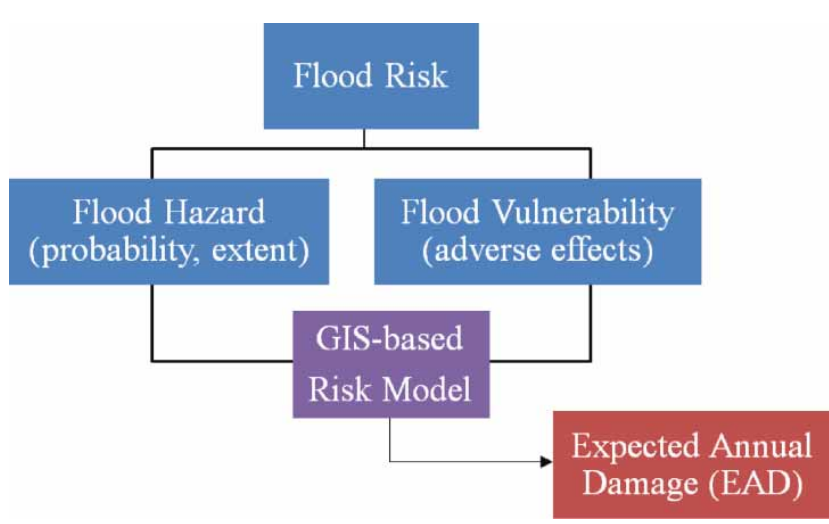

Figure 1 | An overview of the flood risk assessment framework. calculated as the outcome of the risk framework, which is used as the basis for the subsequent economic analysis.

Figure 2 shows the economic framework for assessing the increased risk level due to climate change impacts and the costs and benefits associated with different adaptation options, suggested by e.g. Markandya et al. (2004); Stern (2007) and Zhou et al. (2012). There are two scenarios in the framework: a climate change impacts scenario (CCIS) denoting the change in the EAD due to climate change impacts in the absence of a planned adaptation; and a climate change adaptation scenario (CCAS) where an adaptation cost reduces the EAD. In the framework it is assumed that damage costs due to climate change impacts evolve linearly over time. Benefits are calculated as the reduced flood damage due to a planned adaptation, which corresponds to the area between the CCIS and CCAS curves. The costs are investment costs of adaptation, which are assumed to be implemented immediately at the beginning of the planning horizon, and therefore the benefits are calculated from the point of the investment in time.

The overall rationale of the economic framework is to compare the gross benefits gained from the planned adaptation with its corresponding investment costs. The concept is illustrated in Figure 3, where accumulated marginal benefits (AMB) of a planned adaptation are calculated by assembling the costs and benefits over time. The cost-recovery period of the project can be found at time $t_{\mathrm{NPV}=0}$ (NPV: net present value), where the AMB equals zero. It can be seen that the accumulated marginal benefits are negative until time $t_{\mathrm{NPV}=0}$, indicating the investment costs have not yet been compensated by the adaptation benefits. The investment will generate positive marginal benefits if the technical lifetime of the project is longer than the cost-recovery period. In the context of pluvial flooding a feasible adaptation

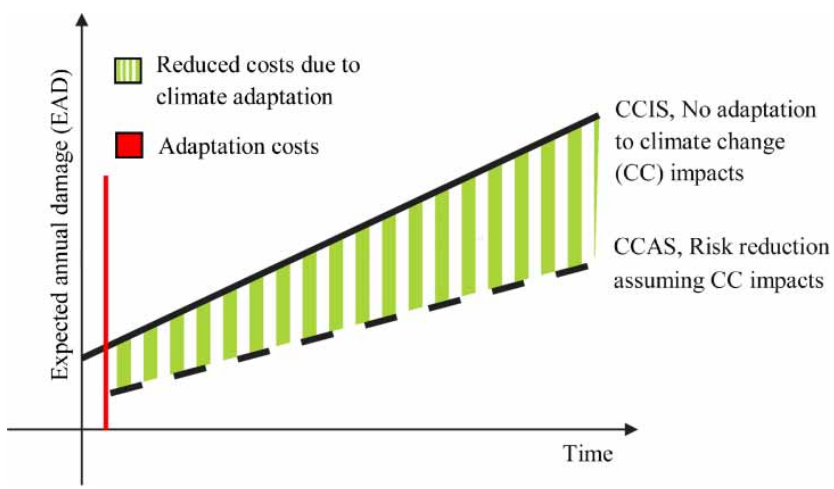

Figure 2 | An overview of the socio-economic framework. The striped area represents the gross benefits due to planned adaptation assuming climate change impacts. 


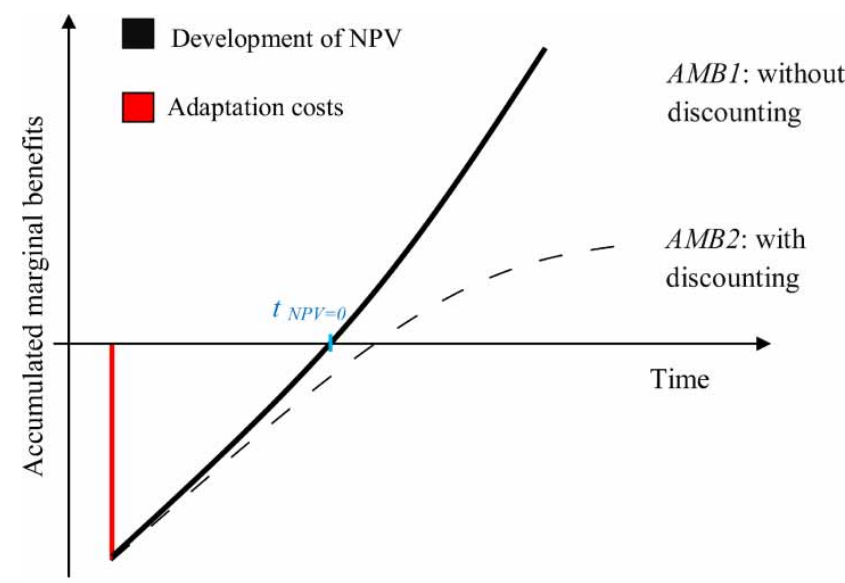

Figure 3 | Conceptual schematic of translation of adaptation benefits and costs into accumulated marginal benefits over time.

seeks to maximize the marginal benefits. In addition, it is noteworthy that both the shape of the AMB curve and the cost-recovery period are sensitive to the choice of the discount rate (Pearce et al. 2006), see an example of the difference between the AMB1 and AMB2 curves in Figure 3. In this case study, a discount rate of $3 \%$ is applied for the economic assessment, which is in line with the rate recommended by the Intergovernmental Panel on Climate Change (IPCC) for long-term investments (with a lifetime of more than 50 years) in climate change projects as well as the Danish EPA guidelines for assessing climate change adaptation options (Damgaard et al. 2006; IPCC 2007).

A range of adaptation options can reduce flood risk by managing hazards and/or vulnerabilities. Depending on the specific local context, flood risk can be reduced by targeting hazards through counteracting the increase in flood frequency or magnitude, and/or by reducing the exposure of vulnerable people or properties to hazards (Burrell et al. 2007; FLOODsite 2009). The adaptation can vary from case to case and its efficiency is very dependent on the main resource and characteristics on the risk.

Climate adaptation can be accomplished in different manners in the context of implementation, e.g. the time of commencement, the durations of adaptation actions, the expected investment costs and benefits (Burrell et al. 2007). To be able to propose a cost-effective option, adaptation should be evaluated by looking at costs and benefits over the planning horizon. Figure 4 shows two main profiles relating to climate change investments: the first profile implies what we can and should do at present in order to adapt to the anticipated climate change impacts (Figure 4(a)). Such an adaptation often involves one or more lumped actions on risk reduction in the near term. However, another strategy can be to choose smaller and more gradual changes, leading to a more gradual investment profile (Figure 4(b)). The latter strategy has some advantages in the sense that the stakeholders will experience an almost constant Expected Annual Cost. However, such annual variations in the expected cost rarely influence decisions and therefore we focus on strategies based on large-lumped investments.

In addition, it can be seen that Figure 4 summarizes the costs (negative) and benefits (positive) in terms of saved costs. The benefits are expressed in terms of avoided flood damage costs, which are assessed as the difference in EAD before and after implementation. In other words, the benefits correspond to the saved EAD due to the planned adaptation (the striped area in Figure 2) in this case.

The inherent uncertainties in analyzing climate change adaptation strategies are large. In principle, uncertainties can be propagated on all states and processes from emission scenarios of greenhouse gases to repairing costs of vulnerable assets. While the quantification of
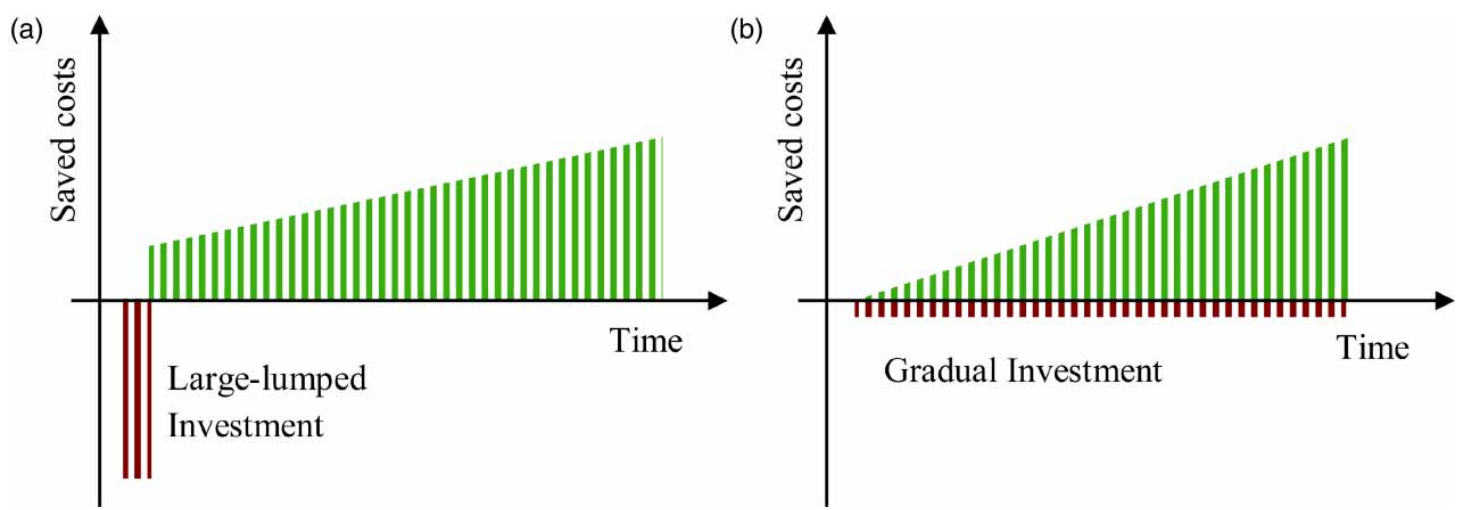

Figure 4 | Two main investment profiles of climate adaptation and their influences on the corresponding benefits. 
these uncertainties is important and must be addressed, it is equally important to recognize that the uncertainties of decision-making are different from the analysis obtained by propagating the uncertainties of the impacts of hazards and vulnerabilities. An example of this difference is highlighted by Gregersen \& Arnbjerg-Nielsen (20I2) showing that decision making in light of uncertain climate change impacts can still be rather robust, because overdesign due to overestimation of climate change impact is compensated by larger future savings on costs of damages. Equally important is to note that risk-based cost-benefit analyses only serve as a guideline and that actual decision making is based on this outcome in combination with other criteria such as preferences of decision makers and compensation structure for stakeholders.

\section{A DANISH CASE STUDY}

\section{Study area}

A Danish case study is used to test three climate adaptation options for urban drainage design. The catchment of Skibhus lies in the north centre of the municipality of Odense, Denmark. The area is about 389 ha with a population of 11,809 people. The catchment consists mainly of single residential houses. Industrial or other commercial activities are not present in the area. The area is well developed indicating that there will be no substantial changes in city layout (e.g. land use) in the foreseeable future and it is very unlikely to experience significant socio-economic and population changes in the area. The area is relatively small and in general it can be assumed that the choice of adaptation strategy will not affect the Danish economy. The sewer network is a combined system and the topography varies from 0 to $20 \mathrm{~m}$ above sea level. The planning horizon is from year 2010 to 2100 .

\section{Climate change impacts}

The anticipated regional effects of climate change were assessed based on a series of Danish studies (Madsen et al. 2009; Arnbjerg-Nielsen 20I2). The study outputs indicate that owing to climate change impacts a $40 \%$ increase is expected in the design intensity of a 100-year-event over a 90-year horizon; and a design intensity currently corresponding to a 10-year event will correspond to a 3.5-year event.

\section{Risk assessment of present and future climates assuming no climate adaptation}

First of all, flood hazard is simulated for the present climate in the absence of climate change and adaptation, see an example of a hazard map of a 100-year event in Figure 5(a). A detailed assessment of flood damage is subsequently carried out in the GIS-based risk model to show the categories and affected by the event, see descriptions of damage categories in the second column in Table 1 . The corresponding flood damage costs are calculated using the unit costs documented by Arnbjerg-Nielsen \& Fleischer (2009). With the flood risk framework, the EAD for the current climate is estimated to be $3.9 \mathrm{MDKK}$ while the EAD in year 2100 is increased to 9.3 MDKK taking into account the climate change impacts. This indicates that there will be an increase of $5.4 \mathrm{MDKK}$ in the EAD in year 2100. In other words, the expected additional damage due to climate change is 239 MDKK from year 2010 to year 2100. This provides the basis for the further cost-benefit analysis of different adaptation options.

\section{Adaptation options}

There are a wide variety of measures to change risk in different manners, which can be categorized into four major groups: (1) flood attenuation, to mitigate and slow down the water runoff, e.g. infiltration and open basins; (2) flood conveyance, to increase the transport capacity of excess water volume, e.g. pipe enlargement, and relief channels; (3) flood regulation and instrument, to reduce the exposure of vulnerable properties to potential hazards, i.e. individual assets protection, flood proofing; and (4) flood defence, by using engineering structures to hold back floods reaching vulnerable areas, e.g. dams, flood walls. In this study, we tested three prevailing applications relevant in the context of pluvial flooding. The adaptation options are pipe enlargement, infiltration, and individual assets protection. Figure 5 shows the description of how each of the adaptation options is implemented in the case study area.

To achieve a better understanding of the individual performance of each measure, we looked into each option individually. Each measure was applied based on two decision criteria: (D1) overall adaptation and (D2) economically optimal adaptation. The first decision criterion is formulated on a basis of equity principle and corresponds to a fixed minimum service level corresponding to no damages at a five-year event in present climate. This decision criterion is in line with the Danish design practice to ensure a fair 

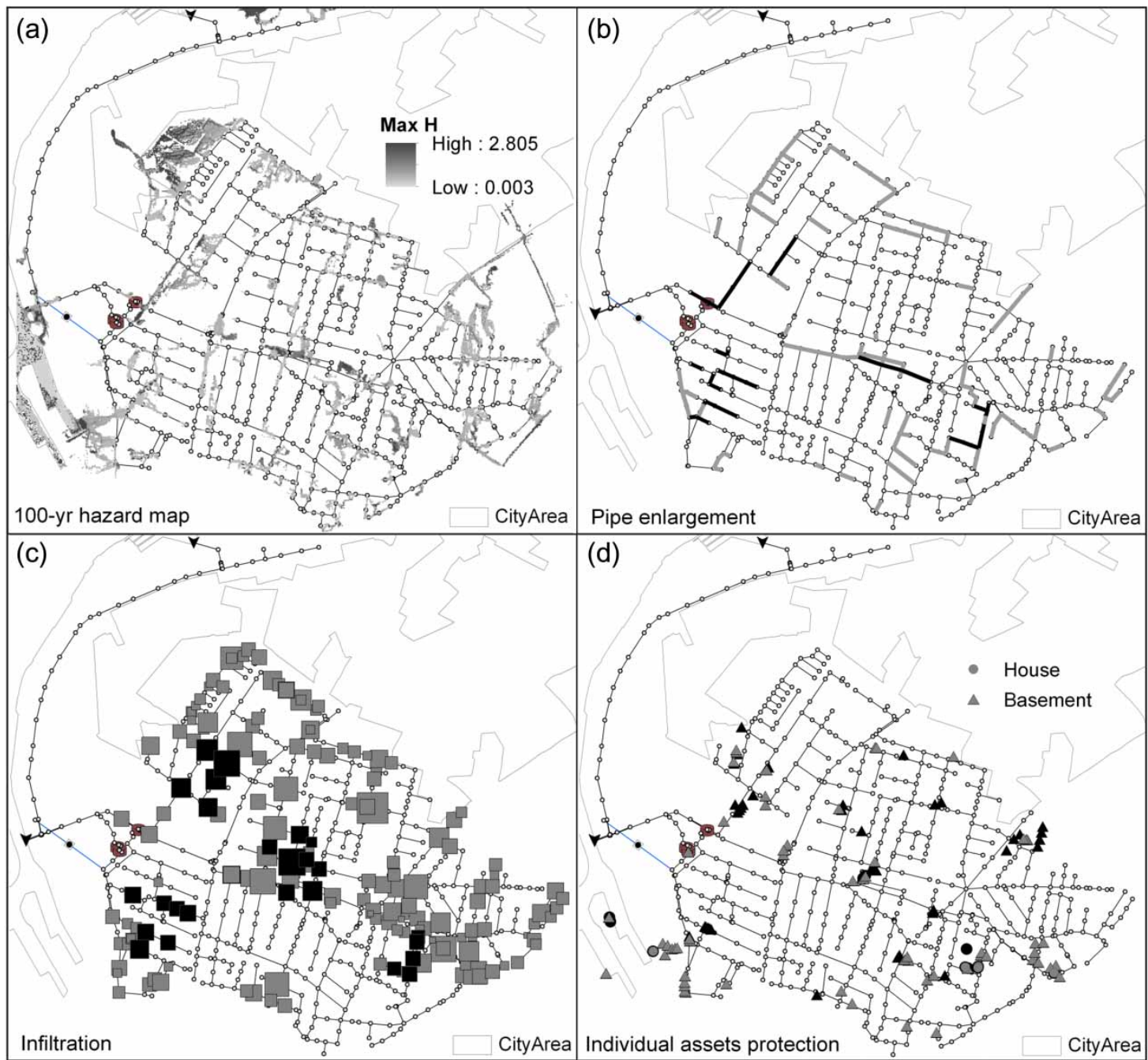

Figure 5 | Illustration of hazard map of a 100-yr event (a) of Skibhus and the application of the three adaptation options (b, c and d). The figures show where measures are needed to comply with the two decision criteria, respectively. The changes in black colour imply the measures needed under both criteria, and the ones in grey are the supplementary measures only needed for decision criterion 1.

Table 1 | Detailed assessments of affected vulnerable categories by a 100-year event before and after implementation of M1 (Pipe enlargement), M2 (Infiltration) and M3 (Individual assets protection) based on the two decision criteria (D1 and D2), respectively

\begin{tabular}{|c|c|c|c|c|c|c|c|}
\hline \multirow[b]{2}{*}{ Damage category } & \multirow[b]{2}{*}{ Original damage } & \multicolumn{3}{|l|}{ D1 } & \multicolumn{3}{|l|}{ D2 } \\
\hline & & M1 & M2 & M3 & M1 & M2 & M3 \\
\hline House & 18 & 8 & 5 & 3 & 8 & 9 & 16 \\
\hline Basement & 267 & 128 & 114 & 73 & 150 & 245 & 240 \\
\hline Traffic delay (hr) & 385 & 245 & 210 & 385 & 322 & 336 & 224 \\
\hline Sewer (manhole) & 31 & 31 & 17 & 31 & 35 & 29 & 19 \\
\hline Lake & 2 & 1 & 1 & 2 & 3 & 1 & 2 \\
\hline Road & 8 & 3 & 3 & 8 & 6 & 7 & 5 \\
\hline
\end{tabular}


hardship of flooding to all stakeholders. However, when adaptation budget constraints exist, the first criterion can be problematic and uneconomical. Once a uniform service level is assigned, in many cases a lot of resources have to be invested to cope with surface flooding in locations where the flood plains are less vulnerable and occupied. This will lead to an ineffective allocation of adaptation investments. Therefore our second criterion only considers adapting in locations where adaptation is economically most profitable from an overall perspective (Zhou et al. 2012). The selection of locations for adaptation is performed based on the aforementioned map showing the vulnerable categories due to pluvial flooding. Priority is given to locations where there are high concentrations of flood damage. The efficiency of a proposed adaptation will then be evaluated using the quantitative flood risk framework to weigh the costs and benefits. In doing so, the proposed adaptation measures are a result of a manual trial and error approach to achieve a reasonable optimization of the marginal benefits of adaptation.

Pipe enhancement indicates an action by utility companies in response to climate change and is modelled by increasing the pipe diameter of the sewer network where relevant. The selection of the new pipe diameter is in accordance with the current design guidelines and based on a trial-and-error approach to obtain a desired hydraulic load in manholes of interest. Infiltration requires higher public involvement and seeks a joint adaptation between the utility companies and the individual stakeholders. It is modelled by detaching subcatchments from the area connected to the sewer system. It is assumed that runoff in the detached subcatchments will infiltrate into ground through infiltration trenches and there is no additional impact on groundwater level due to infiltrated runoffs. Individual assets protection refers to different small-scale measures including the removal of households in high risk zone, installation of anti-flood pump in basements and construction of flood-proofing walls for vulnerable properties. The spatial distribution of these solutions depends upon the exposure of the individual property and the damage function. GIS-based risk maps play an essential role in the approach to provide such information and choosing where and how much adaptation measures should be implemented.

It is assumed that all adaptation measures will be implemented at the beginning of the planning horizon. If the technical lifetimes of some adaptation measures are shorter than the project horizon, a reinvestment is required. All adaptation measures are implemented within five years. For a given adaptation scenario, with the model description of required measures (see examples in Figure 5), we can calculate the adaptation costs by using unit implementation costs provided by municipality and utility companies.

\section{RESULTS AND DISCUSSIONS}

The performances of the applied measures are compared in terms of their efficiency on risk reduction, see Table 1 . The table describes the affected vulnerable categories by a 100 year event before and after implementation of the three adaptation measures under both decision criteria. It can be seen that all applied three measures are capable of reducing flood risk in the catchment. A larger extent of flood damage can be avoided under decision criterion 1 . Nevertheless, it is also important to consider the required costs of implementation when comparing the adaptation performance.

Socio-economic analyses of reduced flood damage and corresponding investment costs of the three proposed adaptation options are shown in Figure 6. As mentioned previously, climate change impacts will lead to negative impacts on flood risks in the area and the saved costs are therefore negative in this case. The results show that more frequent investment is needed for infiltration and individual assets protection approaches due to their short technical lifetimes compared with the sewer system. The lumped investment costs for pipe enlargement and infiltration needed in decision criterion 1 are much higher compared with the private adaptation by individuals. There is less damage saved based on decision criterion 2 for the three options, which indicates that more losses are allowed to occur based on the economically optimal approach.

The evaluation of AMB (with a discount rate of 3\%) of each option is shown in Figure 7. It can be seen that all assessed marginal benefits at the end year are positive, which indicates that in general it would be a rational decision to start adaptation in the catchment. There are higher marginal benefits achieved based on decision criterion 2 , which indicates that smaller upgrading of the system will be more beneficial. In addition, it is noteworthy that in general decision criterion 1 shows a much slower recovery after the costs of implementation, and this is due to the fact that a longer cost recovery period is needed when larger investment costs are assigned. In the particular case, both pipe enlargement and infiltration require more than 50 years to recover the adaptation costs invested under D1. The long recovery time also implies that there is less flexibility to allocate costs for best, use and more uncertainties are involved in the process. This implies that a cost-effective adaptation should choose from options that minimize unnecessary investment costs during the planning horizon. Moreover, the 

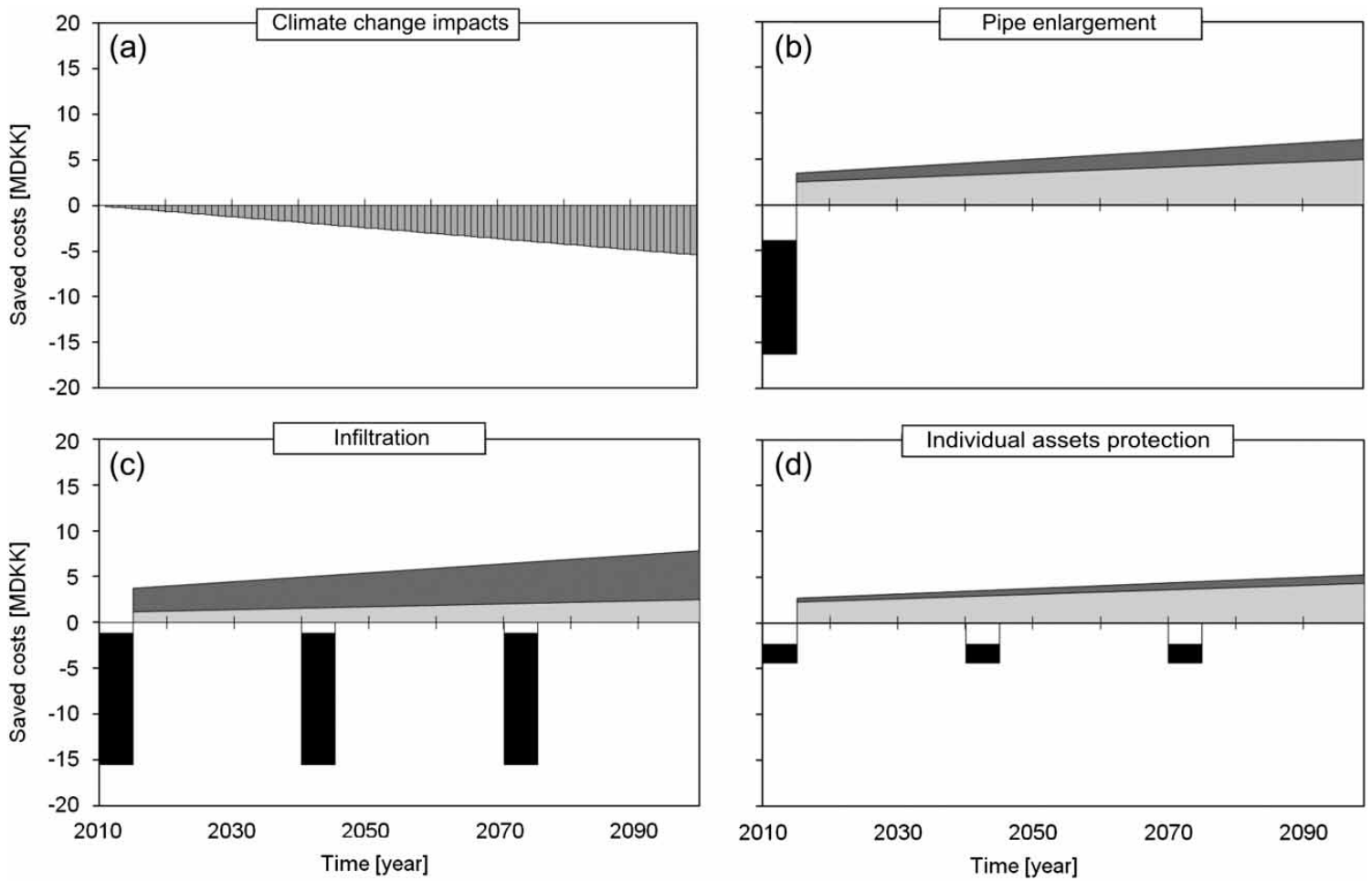

- Adaptation cost_D1

- Saved costs with CC_D1

$\square$ Saved costs_with CC_D2

$\square$ Adaptation costs_D2

Figure 6 | Illustration of investment costs (negative) and saved damage costs (positive) assuming climate change impacts (a) due to adaptation by means of pipe enlargement (b), infiltration (c) and individual assets protection (d) in the socio-economic framework. D1 and D2 denote decision criterion 1 and 2 respectively; CC denotes the climate change impacts.

(a)

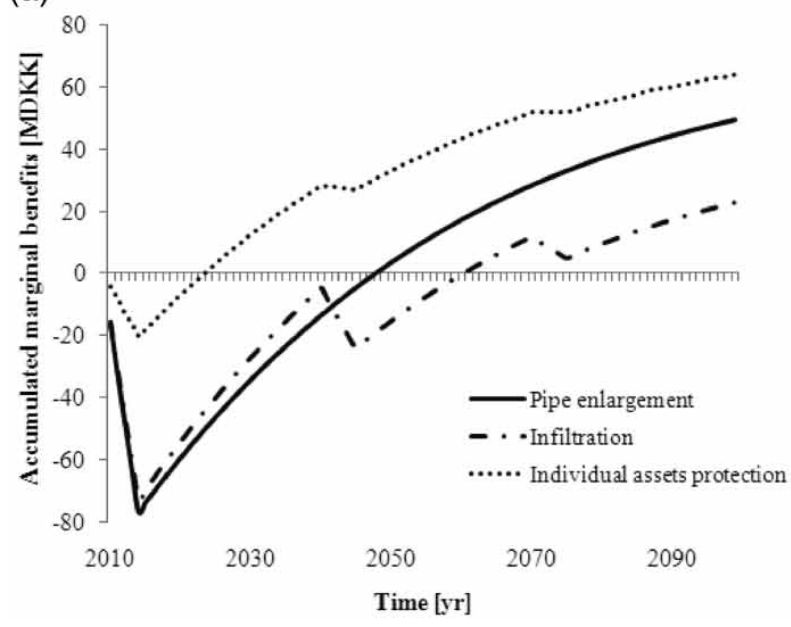

(b)

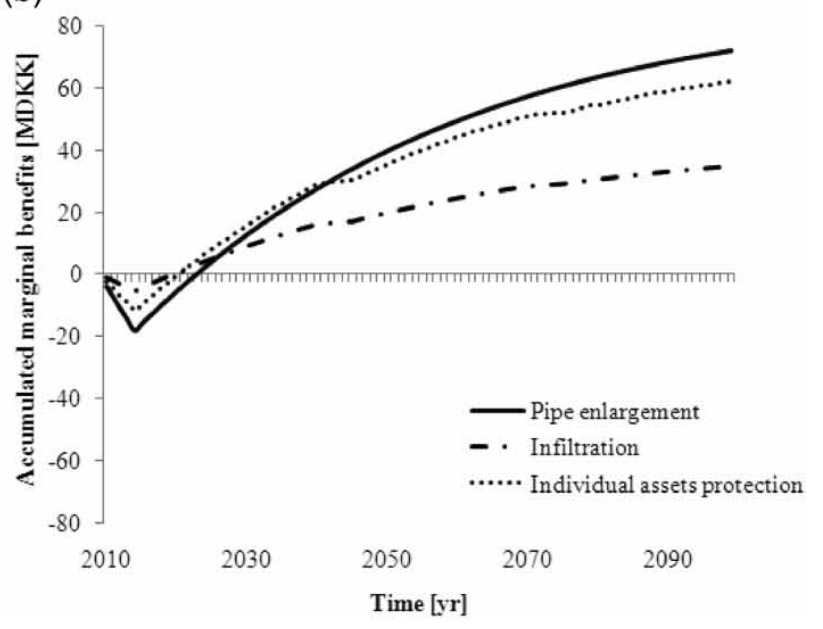

Figure 7 | Accumulated marginal benefits of the three proposed options under both decision criteria.

figure also shows that infiltration is a less cost-effective way in handling climate change in this study. Pipe enlargement can efficiently convey the excess water away from the catchment and is estimated to be more cost-effective. Individual assets protection is shown to be effective in reducing flood risk and protecting individual households from large flood damage losses under the assumption that this strategy can be implemented without risk of errors and malfunctions of the implemented system. 
Besides the technical and economic performance, it is significant to include analysis of social feasibility of adaptation strategies in the decision making process. Ignorance of societal concerns and public perceptions can easily disable interesting solutions (Thompson 2003). Among the three investigated adaptation measures, pipe enlargement is implemented based on the existing centralized system operated at the utility level, which is likely to meet the public perceptions that flood risk should be managed in an 'out of sight, out of mind' manner (Chocat et al. 2004). In contrast, infiltration and individual assets protection imply a significant change in roles in the flood risk management process. Both measures transfer the responsibility of flood management to individual households and require additional investment for implementation. This may entail dissenting voices and scepticism from the householders, thus leading to a policy deadlock. In particular, individual assets protection requires a high level of local participation which is still a highly questionable assumption in the urban water management. For the infiltration measure, the most important scepticism may arise from the fact that the stakeholders to implement the solution do not benefit from the reduced risk of flooding and that they therefore may not be willing to reinvest in maintenance as required in the scenario.

In this study the assessment of costs and benefits associated with climate change adaptation has been simplified, e.g. the maintenance costs are excluded. This means that the real costs for infiltration will be even higher by including the necessary maintenance, while the marginal costs for pipe enlargement are expected to be lower thanks to the rehabilitation and maintenance regularly planned for sewers. A simplified way to justify the operation and maintenance costs in the assessment can be done by adding (or deducting) a proportion of the capital costs on (or from) the investment costs. Furthermore, the environmental costs and political acceptability are not considered in the economic analysis, which may favour the infiltration approach. It is necessary to address the fact that the tested three options are supplementary to each other; a sustainable adaptation demands an integrated approach to maximize the effectiveness.

\section{CONCLUSIONS}

The case study shows that the integrated framework is feasible to identify and evaluate different adaptations in terms of costs and benefits. The method presented is an important decision support tool for climate adaptation for urban drainage design and can be applied for the analysis of other adaptation strategies.

It is found that in general higher marginal benefits and a shorter recovery period can be achieved by neglecting current design principles stipulating minimum flooding frequencies for basements and houses. However, this may not be in accordance with public thinking as the decision criterion implies social inequalities in terms of flood risk management.

The tested three adaptation options indicate that in general it is beneficial to start adaptation in Skibhus. Differences in willingness-to-pay transfer risk and costs between different stakeholders, and differences in needed capital costs may however be more important for actual decision making than the options found to be optimal using the cost-benefit framework.

The study has increased our knowledge of application of feasible adaptation strategies under the more challenging urban contexts. However, the results are not clear. Traditional pipe systems perform well, but not much better than the other two adaptation measures being considered. The main advantage of the sewer system is that it is already present and synergies with existing operation and maintenance costs are possible to obtain, and that a utility company provides a structured basis for transferring risk and resources between stakeholders.

In this study a number of assumptions have been made, in terms of uncertainty related to climate change impacts, city development, and benefits and costs. Future work is needed to quantify these uncertainties and identify which ones are needed for proper decision making.

\section{REFERENCES}

Arnbjerg-Nielsen, K. 2006 Significant climate change of extreme rainfall in Denmark. Water Science and Technology 54 (6-7), 1-8.

Arnbjerg-Nielsen, K. 2012 Quantification of climate change effects on extreme precipitation used for high resolution hydrologic design. Urban Water Journal 9 (2), 57-65.

Arnbjerg-Nielsen, K. \& Fleischer, H. S. 2009 Feasible adaptation strategies for increased risk of flooding in cities due to climate change 1. Water Science and Technology 60 (2), 273-281.

Ashley, R., Garvin, S., Pasche, E., Vassilopoulos, A. \& Zevenbergen, C. 2007 Advances in Urban Flood Management. Taylor \& Francis Group, London, UK.

Ashley, R. M., Balmforth, D. J., Saul, A. J. \& Blanskby, J. D. 2005 Flooding in the future - predicting climate change, risks 
and responses in urban areas. Water Science and Technology 52 (5), 265-273.

Barroca, B., Bernardara, P., Mouchel, J. M. \& Hubert, G. 2006 Indicators for identification of urban flooding vulnerability. Natural Hazards and Earth System Sciences 6 (4), 553-561.

Burrell, B. C., Davar, K. \& Hughes, R. 2007 A review of flood management considering the impacts of climate change. Water International 32 (3), 342-359.

Chocat, B., Ashley, R., Marsalek, J., Matos, M. R., Rauch, W., Schilling, W. \& Urbonas, B. Urban drainage-out-of-sight-outof-mind? In: Proceedings of 5th Int. Conference on Sustainable Techniques and Strategies in Urban Water Management, Lyon, France, 6-10 June 2004.

Damgaard, C., Strandmark, L., Heideman, R., Nielsen, T. \& Emborg, L. 2006 Recommended Methodology in Relation to Socio-Economic Assessment of Adaptation to Climate Change. Danish EPA, Copenhagen.

Dawson, R. J., Dickson, M. E., Nicholls, R. J., Hall, J. W., Walkden, M. J. A., Stansby, P. K., Mokrech, M., Richards, J., Zhou, J., Milligan, J., Jordan, A., Pearson, S., Rees, J., Bates, P. D., Koukoulas, S. \& Watkinson, A. R. 2009 Integrated analysis of risks of coastal flooding and cliff erosion under scenarios of long term change. Climatic Change 95 (1-2), 249-288.

European Commission 2009 White paper - Adapting to climate change: towards a European framework for action. Available from: http://eur-lex.europa.eu/LexUriServ/LexUriServ.do? uri=CELEX:52009DC0147:EN:NOT. Visited 10th December, 2010.

FLOODsite 2009 Flood Risk Assessment and Flood Risk Management. An Introduction and Guidance Based on Experiences and Findings of FLOODsite (an EU-funded Integrated Project). Deltares|Delft Hydraulics, Delft, The Netherlands.

Gregersen, I. B. \& Arnbjerg-Nielsen, K. 2012 Decision strategies for handling the uncertainty of future extreme rainfall under influence of climate change. Water Science and Technology 66 (2), 284-291.

Hall, J. W., Sayers, P. B., Walkden, M. J. A. \& Panzeri, I. 2006 Impacts of climate change on coastal flood risk in England and Wales: 2030-2100. Philosophical Transactions of the Royal Society A-Mathematical Physical and Engineering Sciences 364 (1841), 1027-1049.

Hauger, M. B., Mouchel, J. M. \& Mikkelsen, P. S. 2006 Indicators of hazard, vulnerability and risk in urban drainage. Water Science and Technology 54 (6-7), 441-450.
Haynes, H., Haynes, R. \& Pender, G. 2008 Integrating socio-economic analysis into decision-support methodology for flood risk management at the development scale (Scotland). Water and Environment Journal 22 (2), 117-124.

IPCC 2007 Climate Change 2007: Mitigation of Climate Change. Contribution of Working Group III to the Fourth Assessment Report of the IPCC. Cambridge University Press, Cambridge, UK.

Jones, R. H., Westra, S. \& Sharma, A. 2oIo Observed relationships between extreme sub-daily precipitation, surface temperature, and relative humidity. Geophysical Research Letters 37, L22805, 5pp.

Jonkman, S. N., Bockarjova, M., Kok, M. \& Bernardini, P. 2008 Integrated hydrodynamic and economic modelling of flood damage in The Netherlands. Ecological Economics 66 (1), 77-90.

Lenderink, G. \& Van Meijgaard, E. 2008 Increase in hourly precipitation extremes beyond expectations from temperature changes. Nature Geoscience 1 (8), 511-514.

Madsen, H., Arnbjerg-Nielsen, K. \& Mikkelsen, P. S. 2009 Update of regional intensity-duration-frequency curves in Denmark: Tendency towards increased storm intensities. Atmospheric Research 92 (3), 343-349.

Markandya, A., Hunt, A., Boyd, R. \& Taylor, T. 2004 Metodologia para valorar los costes de los impactos del cambio climatico (Methodology for costing the impacts of climate change). Ekonomiaz, UK, pp. 164-215.

Morita, M. 2008 Flood risk analysis for determining optimal flood protection levels in urban river management. Journal of Flood Risk Management 1 (3), 142-149.

Pearce, D., Atkinson, G. \& Mourato, S. 2006 Cost-Benefit Analysis and the Environment: Recent Developments. OECD, France.

Plate, E. J. 2002 Flood risk and flood management. Journal of Hydrology 267 (1-2), 2-11.

Stern, N. 2007 The Economics of Climate Change. The Stern Review. Cambridge University Press, Cambridge, UK.

Thompson, M. 2003 Cultural theory, climate change and clumsiness. Economic and Political Weekly 38, 5107-5112.

Zhou, Q., Mikkelsen, P. S., Halsnæs, K. \& Arnbjerg-Nielsen, K. 20I2 Framework for economic pluvial flood risk assessment considering climate change effects and adaptation benefits. Journal of Hydrology 414-415, 539-549. 